\title{
Comparative evaluation of modified proximal perineal urethrostomy with direct guided urethral catheterisation and tube cystostomy for the management of obstructive urolithiasis in male goats
}

\author{
Anvitha Hansoge ${ }^{1}$, Sudheesh S Nair ${ }^{2}$, Soumya Ramankutty², B. Lavanya1, \\ M.K. Praveen ${ }^{1}$, J. Sharath ${ }^{1}$, J. Deny ${ }^{1}$, M.K. Narayanan ${ }^{3}$ and K.D. John Martin ${ }^{4}$ \\ Department of Veterinary Surgery and Radiology, College of Veterinary and Animal Sciences, \\ Mannuthy, Thrissur Kerala Veterinary and Animal Sciences University, India.
}

Citation: Anvitha, H., Nair, S.S., Soumya, R., Lavanya, B., Praveen, M.K., Sharath, J., Deny, J., Narayanan, M.K. and John Martin, K.D. 2021. Comparative evaluation of modified proximal perineal urethrostomy with direct guided urethral catheterisation and tube cystostomy for the management of obstructive urolithiasis in male goats. J. Vet. Anim. Sci. 52(2): 131-134.

DOI: https://doi.org/10.51966/jvas.2021.52.2.131-134

Received: 10.12 .2020

Accepted: 10.01.2021

Published: 01.06 .2021

\begin{abstract}
Twelve clinical cases of chronic obstructive urolithiasis in male goats were selected for the study with the objective to evaluate two surgical techniques - modified proximal perineal urethrostomy (MPPU) with direct guided urethral catheterisation (Group I) and tube cystostomy (Group II) for the surgical management. Ultrasonography was effective in assessing the urinary bladder and detection of uroliths. Functional patency of normal urethra was regained in five out of six animals of each group by third post-operative week. Direct access to the perineal urethra providing quick relief to the turgid bladder was identified as the major advantage of modified proximal perineal urethrostomy technique. Tube cystostomy technique provided direct visual assessment of urinary bladder, precise fixing of Foley's catheter and retrieval of uroliths. Even though this technique was found to be more invasive, it was identified as an effective approach for correcting cystorrhexis resulted from obstructive urolithiasis
\end{abstract}

Key words: Modified proximal perineal urethrostomy, tube cystostomy, obstructive urolithiasis

Urolithiasis is defined as the formation of uroliths as a consequence of multiple congenital and/or acquired pathophysiologic processes that resulted in the increased concentration of less soluble crystalloids in the urine (Dar, 2011). Many surgical procedures like amputation of urethral process, urethrotomy, urethrostomy, cystotomy, tube cystostomy and bladder marsupialization

Part of M.V.Sc. thesis submitted by the first author to the Kerala Veterinary and Animal Sciences University, Pookode, Wayanad, Kerala

1. M.V.Sc. student email : hansoge@gmail.com Ph. 9590125001

2. Assistant Professor and corresponding author: email: sudheeshnair@kvasu.ac.in, Ph. 7012782977

3. Professor

4. Professor and Head

Copyright: (C) 2021 Anvitha Hansoge et al. This is an open access article distributed under the terms of the Creative Commons Attribution 4.0 International License (http://creativecommons.org/licenses/by/4.0/), which permits unrestricted use, distribution, and reproduction in any medium, provided the original author and source are credited. 
were documented by various authors for successful management of urolithiasis. (Ewoldt et al., 2008).

Tube cystostomy has been considered a gold standard technique - due to its direct access to the urinary bladder whereas modified proximal perineal urethrostomy (MPPU) using direct guided urethral catheterisation technique is emerging as new technique to approach urethral access with a stylet guided catheter through a specific site between the pin bones at the level of about two $\mathrm{cm}$ below the anus (Nair et al., 2020).

\section{Materials and Methods}

Twelve male goats with obstructive urolithiasis were presented to the Veterinary Hospitals were divided into two groups. Group I (six animals) were subjected to modified proximal perineal urethrostomy and Group II (six animals) were subjected to tube cystostomy.

The general condition of the goats, condition of urethral process, perineal urethral pulsation and ultra-sonographic evaluation of the urinary bladder was carried out on the day of presentation in all the goats as per the procedure documented by Braun et al. (1992.)
Fig-1. Modified Perineal Urethrostomy) using direct guided urethral catheterisation technique

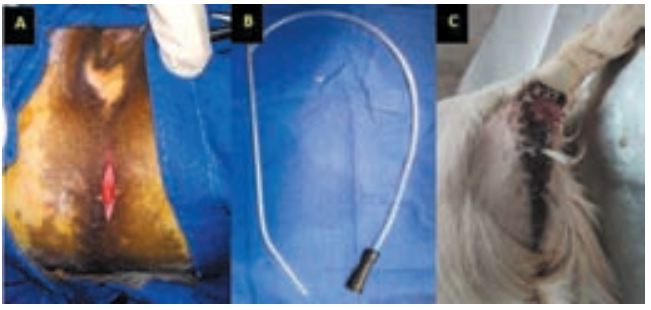

Fig-2. Tube cystostomy technique

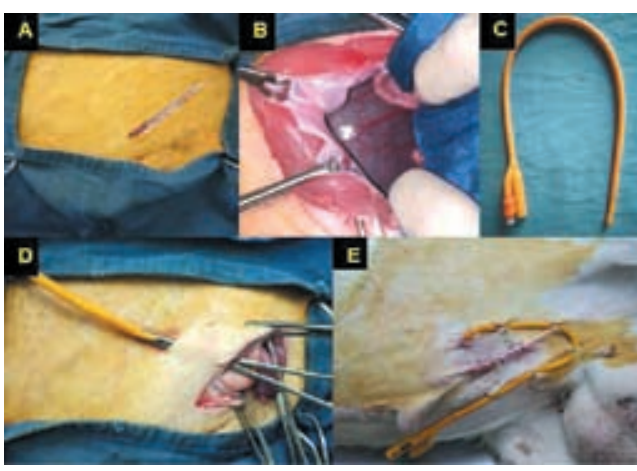

In animals of group I, regional anaesthesia was achieved by caudal epidural anaesthesia using $2 \%$ lignocaine hydrochloride, with animals restrained in sternal recumbency and tail fixed cranially and perineum elevated.

Table 1: Comparison of the surgical techniques of MPPU and Tube cystostomy in chronic obstructive urolithiasis in goats

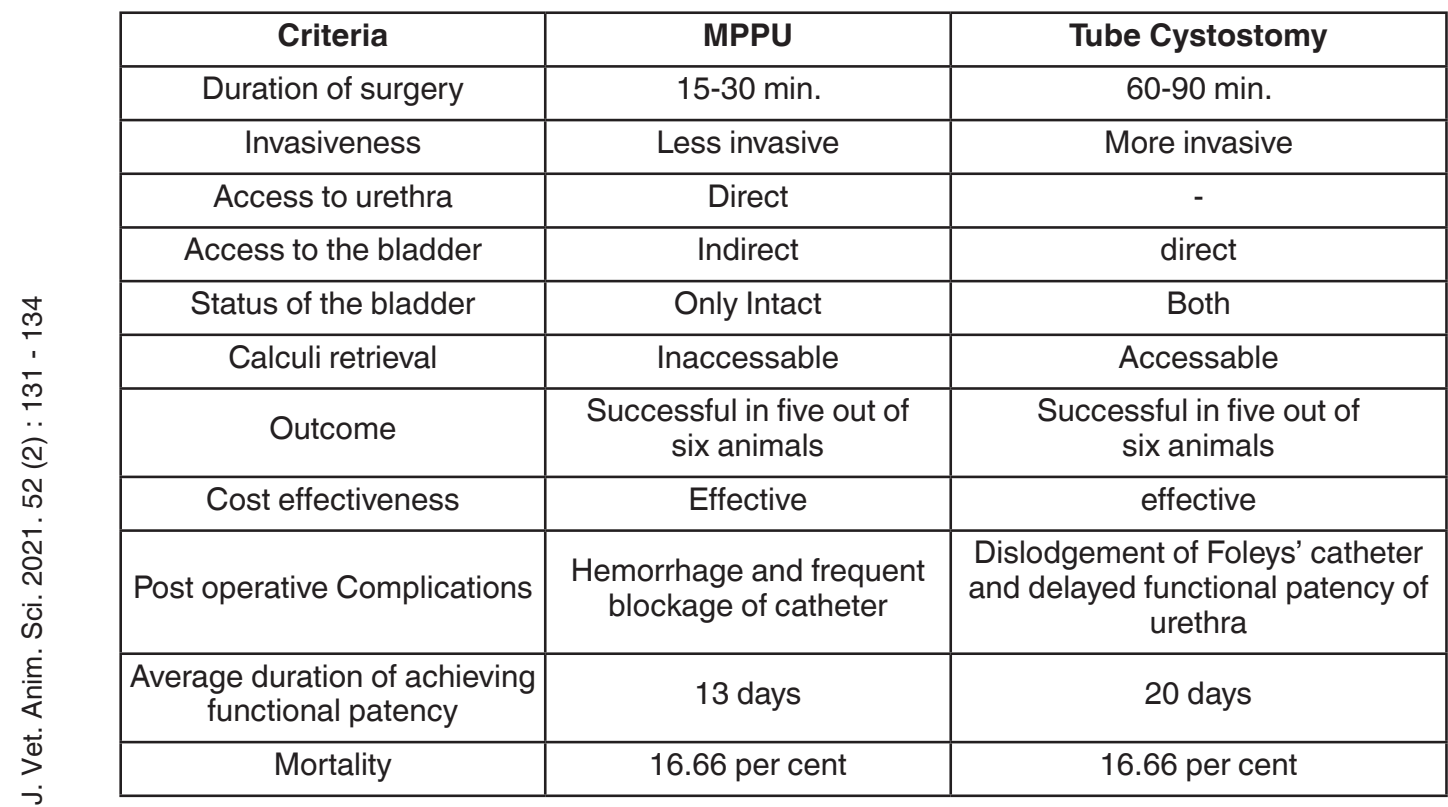

132 Comparative evaluation of modified proximal perineal... 
Modified catheter was fabricated and by passing a pre bent K-wire introduced into the lumen of an infant feeding tube of suitable size (Fig -1B). A one centimetre long incision commencing from two centimetres below the anal opening, between the pin bones was made to identify the pulsating urethra. (Fig-1A). A modified stented catheter was introduced by gentle puncture into the urethral lumen to reach the bladder following which the K-wire was withdrawn and the catheter was fixed in situ. (Fig- 1C)

Animals of Group II were sedated by inj. xylazine hydrochloride at $0.05 \mathrm{mg} /$ $\mathrm{kg}$ body weight intramuscularly and regional anaesthesia was achieved with inverted ' $\mathrm{L}$ ' block using $2 \%$ lignocaine hydrochloride. The animals were restrained in right lateral recumbency with the hind limbs extended backwards. Tube cystostomy was performed as per the technique described by Gazi et al. (2014). A three-inch oblique lower flank incision was made on the skin. Subcutaneous fascia and rectus abdominis muscles were separated followed by peritoneum to enter the abdomen (Fig- 2A). The bladder was isolated and exteriorized and an incision was made to retrieve the calculi and lavage the bladder (Fig2B). A ballooned Foley's catheter of size 16 FG made of rubber latex was used as an indwelling catheter for tube cystostomy (Fig-2C). A nick incision was made three centimetre lateral to the flank incision on the skin and a curved artery forceps was passed from the abdomen penetrating through all the muscle layers to facilitate the drawing of the catheter from outside to inside (Fig- 2D). A nick incision was made on the bladder away from the cystotomy closure and the tip of the catheter was inserted to the bladder. The balloon part of the catheter was then inflated with $5 \mathrm{ml}$ of normal saline to keep the catheter tip locked inside the bladder and secured with purse-string sutures. The cystotomy closure was performed using double inversion sutures of Cushing's followed by Lembert pattern, abdomen closure was performed using Polyglactin- 910 sutures in a continuous pattern and skin sutures were performed using Nylon 1-0 in the interrupted pattern. The Foley's catheter was fixed to the skin and left in situ (Fig-2E) till functional patency of the urethra was regained.
Post-operatively, the animals were administered Inj. Enrofloxacin at the dose rate of $5 \mathrm{mg} / \mathrm{kg}$ body weight for seven days and Inj. tramadol at the dose rate of $2 \mathrm{mg} / \mathrm{kg}$ body weight for three days. Ammonium chloride at $300 \mathrm{mg} / \mathrm{kg}$ body weight was supplemented after confirming the alkalinity of the urine.

\section{Results and Discussion}

In Group I, the MPPU catheters were removed on second post-operative week in three animals and third post-operative week in two animals after confirming the functional patency of urethra, characterised by free flow of urine through the normal urethral opening. Even though urinary diversion was successfully achieved in all the animals in this group, only five out of six animals showed complete healing. One animal had severe operative site infection with perineal abscess and died on fifth post-operative week.

In group II, the urethral patency was restored in five out of six animals by the end of third to fourth post-operative week. Two animals had bladder rupture and catheter got dislodged with severe cystitis and uroabdomen. One animal died on fourth post-operative week.

Ultrasonography of the bladder revealed anechoic distended bladder with multiple hyperechoic sediments. Thinning of the bladder was appreciated in 10 goats and results were in accordance with Al-Lugami et al. (2017).

In animals of group-I, the pulsating perineal urethra was easy to access through a site below the anal opening between the pin bones in the procedure adopted. In the present study, bending of the MPPU catheter by passing a prebent $\mathrm{K}$ Wire into the lumen favored bypass of urethral diverticulum as reported by Fortier et al. (2004). Moderate perineal bleeding was seen as in three out of six cases out of which one animal had severe bleeding during and after the procedure. This could be due to the injury to the dorsal penile and external pudental artery running closely in alignment with the course of urethra as reported by Oman et al. (2019).

Direct lavaging of the urinary bladder 
was possible by this technique which facilitated the alkaline $\mathrm{pH}$ correction by flushing the urinary bladder with two per cent boric acid solution. Five animals recovered by this technique by the end of three weeks and the catheters were removed after confirming the normal urethral patency. This was in accordance with Nair et al. (2020)

An oblique left lower flank incision performed in group I resulted in cystorrhexis in one and severe cystitis was detected in four animals. In cases of cystorrhexis, uroabdomen was noticed and the fluid was gradually relieved to avoid shock. An extension of the surgical site more caudally was done to identify the site of ruptured bladder.

The dislodgement of the catheter from the skin and bladder was another complication of the - group II animals. Delayed functional patency of urethra was noticed in three animals in which the animals were able to pass urine through normal opening by fourth post-operative week. Obstruction of Foley's catheter was found in one animal - which was relieved by flushing with normal saline and two per cent boric acid solution. Four animals started passing urine normally by second post-operative week while urethral patency was re-established by the end of three weeks in two animals.

\section{Conclusion}

Owing to the ease of access to the proximal perineal urethra, evident perineal pulsation, minimal surgical trauma and precise placement of the catheter in less time, modified proximal perineal urethrostomy could be a highly effective technique in managing caprine obstructive urolithiasis. Deliberate skill for the precise location of the urethra warrants the success of this technique. The correct selection of the size of the catheter, the landmark of the urethral puncture were the main challenges identified in this technique. Tube cystotomy offered the direct visualisation of the bladder and hence an effective fixation of Foleys' catheter was possible. Due to the direct access to the bladder, this procedure could be regarded as the only surgical option in cases of cystorrhexis due to obstructive urolithiasis. Partial dislodgement of the fixation of the catheter and mild oedema at the surgical site were the only identified complications in tube cystostomy.

\section{References}

Al-Lugami, A., von Pückler, K., Wehrend, A. and Sickinger, M. 2017. Sonography of the distal urethra in lambs. Acta Veterinaria Scandinavica. 59: 1-6.

Braun, U., Schefer, U. and Fohn, J. 1992. Urinary tract ultrasonography in normal rams and in rams with obstructive urolithiasis. Can. Vet. J. 33: 654-659.

Dar, F.A. 2011. Evaluation and management of urolithiasis in goats. MVSc thesis, Kerala Veterinary and Animal Sciences University, Pookode. 1-34p.

Ewoldt, J.M., Jones, M.L. and Miesner, M.D. 2008. Surgery of obstructive urolithiasis in ruminants. Vet. Clin. North Am. Food Anim. 24: 455-465.

Fortier, L.A., Gregg, A.J., Erb, H.N. and Fubini, S.L.2004.Caprineobstructiveurolithiasis: requirement for 2 nd surgical intervention and mortality after percutaneous tube cystostomy, surgical tube cystostomy, or urinary bladder marsupialization. Vet. Surg. 33: 661-667.

Gazi, M.A., Makhdoomi, D.M., Parrah, J.D., Ganai, A.M., Shiekh, G.N. and Mir, S.A. 2014. Recent advances in surgical management of urolithiasis in sheep and goat. Afr. J. Agri. Res. 9: 2055-2061.

Nair, S.S., Ramankutty, S., Hansoge, A., Narayanan, M.K. and Devanand, C.B. 2020. Modified Proximal Perineal Urethrostomy (MPPU) using Novel Direct Guided Urethral Catheterisation Technique for Early Management of Obstructive Urolithiasis in Male Goats. Int. J. Livest. Res. 10: 69-74.

Oman, R.E., Reppert, E.J., Streeter, R.N. and Jones, M. 2019. Outcome and complications in goats treated by perineal urethrostomy for obstructive urolithiasis: 25 cases (2010-2017). J. Vet. Intern. Med. 33: 292-296. 